\title{
A vulnerability paradox in the cross-national prevalence of post-traumatic stress disorder
}

\author{
Michel L. A. Dückers, Eva Alisic and Chris R. Brewin
}

\section{Background}

Determinants of cross-national differences in the prevalence of mental illness are poorly understood.
Aims
To test whether national post-traumatic stress disorder (PTSD) rates can be explained by (a) rates of exposure to trauma and (b) countries' overall cultural and socioeconomic vulnerability to adversity.

\section{Method}
We collected general population studies on lifetime PTSD and trauma exposure, measured using the WHO Composite International Diagnostic Interview (DSM-IV). PTSD prevalence was identified for 24 countries (86687 respondents) and exposure for 16 countries (53038 respondents). PTSD was predicted using exposure and vulnerability data.

\section{Results}

PTSD is related positively to exposure but negatively to country vulnerability. Together, exposure, vulnerability and their interaction explain approximately $75 \%$ of variance in the national prevalence of PTSD.

\section{Conclusions}

Contrary to expectations based on individual risk factors, we identified a paradox whereby greater country vulnerability is associated with a decreased, rather than increased, risk of PTSD for its citizens.

\section{Declaration of interest}

None.

\section{Copyright and usage}

(c) The Royal College of Psychiatrists 2016.
Whereas a considerable amount is known about individual-level risk factors for post-traumatic stress disorder (PTSD), which include trauma exposure and indices of vulnerability such as social and educational disadvantage, ${ }^{1-3}$ there has been little research into country-level predictors. Initial concerns that PTSD was a specifically Western formulation of response to trauma have been allayed by cross-national research indicating that although there is some cultural patterning of symptoms the condition occurs around the world. ${ }^{4}$ Despite this evidence for cross-cultural validity, however, there are relatively large unexplained variations in PTSD rates across countries, with lifetime prevalence in general populations ranging from zero to more than $6 \% .^{5}$ Our objective was to test whether national differences in lifetime PTSD prevalence can be explained by countries' rates of exposure to trauma and their vulnerability, both singly and in interaction. The interaction has been suggested, for instance, by Cutter: 'Vulnerability is the likelihood that an individual or group will be exposed to and adversely affected by a hazard. It is the interaction of the hazards of place (risk and mitigation) with the social profile of communities. ${ }^{6}$ The specific vulnerability of nations to major disturbances such as disasters has recently been captured in a comprehensive combination of cultural and socioeconomic country features. ${ }^{7}$ There is consistent evidence that within countries more disadvantaged groups have higher prevalence levels of PTSD in response to trauma exposure. ${ }^{8,9}$ These approaches suggest that more vulnerable countries should have higher prevalence rates, and that trauma exposure interacts with group vulnerability to increase PTSD prevalence.

\section{Method}

\section{Country-level data on prevalence of lifetime PTSD and exposure to trauma}

In order to ensure quality and standardise measurement of trauma and PTSD we selected studies using the Composite International Diagnostic Interview (CIDI). ${ }^{10}$ The CIDI is a widely used structured diagnostic interview, validated cross-culturally and designed to be used by trained lay interviewers. ${ }^{10,11}$ It was the main measure of the World Mental Health (WMH) surveys. Trauma exposure is measured using detailed lists of events including, among others, combat or war experience, natural disaster, physical or sexual assault, physical abuse as a child, motor vehicle accident, unexpected death or life-threatening illness of a loved one and witnessing a potentially traumatic event. ${ }^{12,13}$

We searched Medline, EMBASE, PsycINFO and PILOTS for prevalence studies on lifetime PTSD and exposure to trauma, conducted in representative samples with a CIDI-based assessment of PTSD according to the DSM-IV criteria. The literature databases were searched in the second half of January 2015 using the following combination of search terms: (a) trauma-related (for example 'PTSD', 'posttraumatic stress', 'post-traumatic stress', 'traumatic', 'trauma') and (b) prevalence in all fields, together with (c) 'lifetime' and (d) 'Clinical International Diagnostic Interview' or 'CIDI' in title and abstract. We did not apply restrictions regarding language, publication type or date of publication. Reference lists were inspected to identify other potentially relevant studies. Studies focusing solely on 12-month PTSD prevalence, using older DSM versions or not using the CIDI, were excluded. Where we found more than one data-set for any country meeting the inclusion criteria we selected the most recent one.

\section{Country vulnerability}

In the annual World Risk Report, produced by Alliance Development Works, the UN University and the University of Bonn, a broad collection of data-sets are brought together and combined into a vulnerability index, reflecting a variety of social and economic country features. ${ }^{7}$ In the 2013 report, the vulnerability of 173 countries was summarised using 23 indicators, divided into three components, and measured using worldwide and publicly accessible data. ${ }^{7}$ Susceptibility describes a country's structural characteristics and framework conditions that can sustain harm. For example, 
indicators involve malnutrition, access to sanitation, income equality and gross domestic product per capita. Lack of coping capacity refers to the ability of a country to minimise negative impacts of events and includes indicators such as number of physicians and hospital beds per 1000 inhabitants and the Corruption Perceptions Index. Lack of adaptive capacities refers to conditions supporting long-term, structural change. Example indicators include the adult literacy rate, combined gross school enrolment, forest management and public and private health expenditure. More background information on the index, its composition and analysis can be found in the World Risk Report of $2013 .^{7}$

\section{Analysis}

We calculated correlation coefficients and tested four linear regression models with lifetime PTSD as dependent variable. Models with one predictor, exposure or vulnerability, were followed by a model with both predictors and a final model to test whether the relationship between exposure and PTSD was moderated by a country's level of vulnerability. We verified that associations were not affected by survey response rates. All analyses were performed in IBM SPSS Statistics, version 20 .

\section{Results}

We found 24 studies meeting our inclusion criteria (86687 respondents). Exposure to trauma could be determined for 16 countries (53 038 respondents). Information about each study is displayed in online Table DS1. All studies were published between 2005 and 2014, based on surveys administered between 2001 and 2007 , with an average response rate of $70.9 \%$. Most of them were conducted using CIDI version 3.0 (87.5\%). The highest PTSD prevalence rates were found in Canada, The Netherlands and Australia, the lowest in Nigeria, China, and Romania (Fig. 1). Exposure to trauma was the highest in The Netherlands, Colombia and the USA and the lowest in Romania, Spain and Italy. Besides lifetime PTSD and exposure to trauma, online Table DS1 also contains the country vulnerability score. The most vulnerable countries were Nigeria, Iraq and Colombia and the least vulnerable were The Netherlands, Germany and Belgium.

Table 1 shows distributional and correlational information for the study variables. Lifetime PTSD in the various country samples was correlated positively with exposure to trauma and negatively with vulnerability. Exposure and vulnerability were not related.

The results of the regression analyses are detailed in Table 2 and Fig. 2. Exposure to trauma was a significant positive predictor

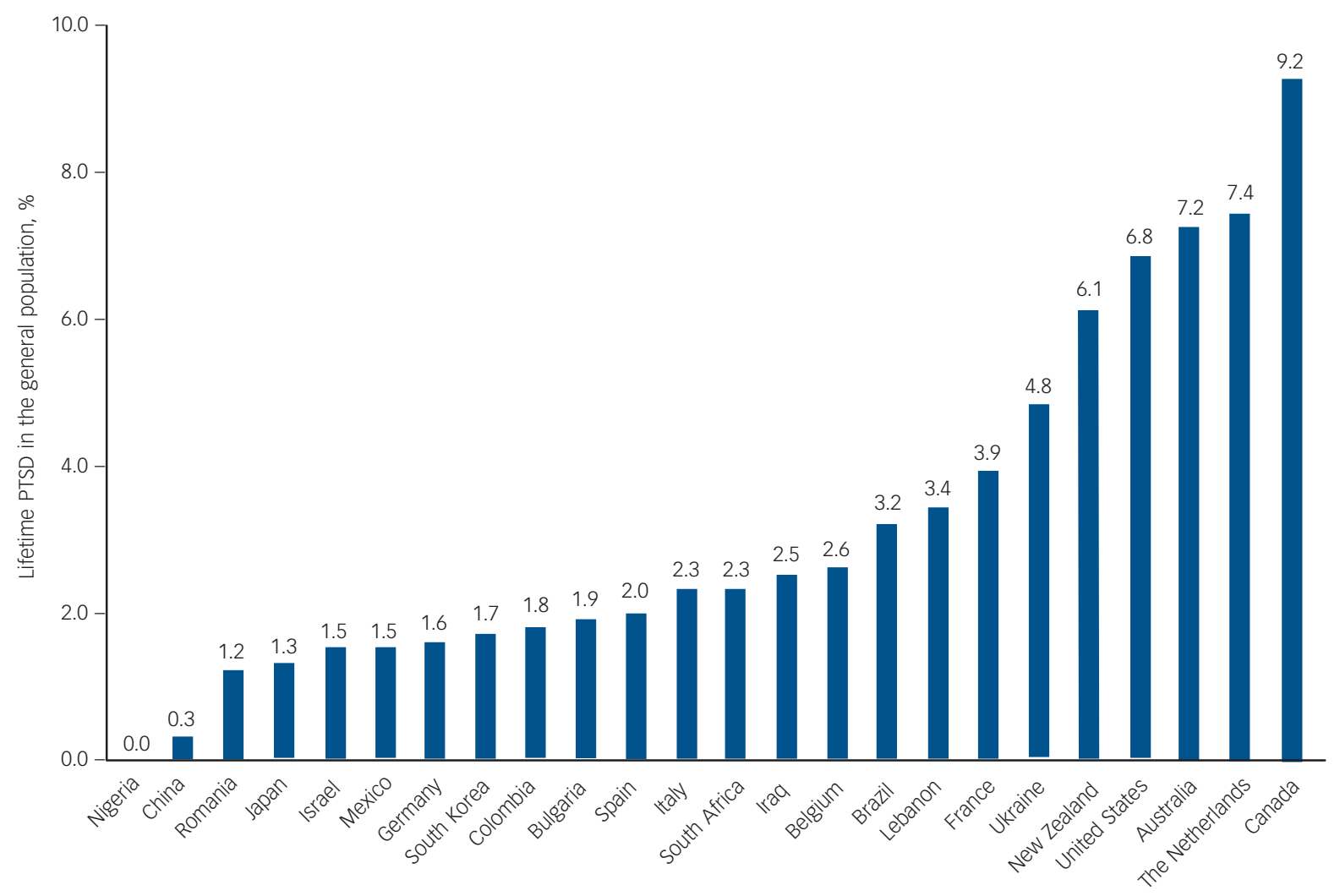

Fig. 1 Lifetime post-traumatic stress disorder (PTSD) prevalence in 24 countries $(\%, n=86687)$.

\begin{tabular}{|c|c|c|c|c|c|c|c|}
\hline & \multicolumn{5}{|c|}{ Distributional information } & \multicolumn{2}{|c|}{ Correlations } \\
\hline & Study, $n$ & Mean & Median & IQR & Minimum-Maximum & \% lifetime PTSD & $\%$ exposure to trauma \\
\hline \% lifetime PTSD & 24 & 3.21 & 2.30 & 3.18 & $0.00-9.20$ & - & \\
\hline$\%$ exposed to trauma & 16 & 67.14 & 70.30 & 18.43 & $41.50-80.70$ & $0.60^{*}$ & - \\
\hline Vulnerability score & 24 & 39.34 & 36.63 & 15.50 & $28.39-68.99$ & $-0.49^{*}$ & 0.05 \\
\hline
\end{tabular}


for PTSD, accounting for approximately one-third of the variance (model 1, 16 countries). In contrast, country vulnerability was a significant negative predictor, explaining roughly a quarter of the variance (model 2, 24 countries). When both variables were included simultaneously in model 3 (16 countries), the effects of each remained significant and the explained variance increased to around $60 \%$. Model 4 (16 countries) showed that, in addition to the main effects, the relation between trauma exposure and lifetime PTSD was significantly moderated by vulnerability such that high exposure was only associated with high PTSD prevalence

\begin{tabular}{|c|c|c|c|c|}
\hline & $\begin{array}{c}\text { Model } 1 \\
\text { (exposure) }\end{array}$ & $\begin{array}{c}\text { Model } 2 \\
\text { (vulnerability) }\end{array}$ & $\begin{array}{c}\text { Model } 3 \\
\text { (exposure } \\
\text { and vulnerability) }\end{array}$ & $\begin{array}{c}\text { Model } 4 \\
\text { (exposure, vulnerability } \\
\text { and interaction) }\end{array}$ \\
\hline \multicolumn{5}{|l|}{ Coefficients (95\% Cl) } \\
\hline Intercept & $-5.470(-12.470$ to 1.530$)$ & $7.715^{* *}$ (4.075 to 11.354$)$ & $0.669(-6.487$ to 7.825$)$ & $-39.068^{*}(-68.610$ to -9.526$)$ \\
\hline Exposure & $0.136 *$ (0.033 to 0.238) & - & $0.142^{* *}$ (0.059 to 0.225$)$ & $0.701 * *(0.288$ to 1.114$)$ \\
\hline Vulnerability & - & $-0.115^{\star}(-0.205$ to -0.026$)$ & $-0.181^{*}(-0.311$ to -0.051$)$ & $0.903 *(0.106$ to 1.701$)$ \\
\hline Exposure $\times$ vulnerability & - & - & - & $-0.015^{\star}(-0.026$ to -0.004$)$ \\
\hline \multicolumn{5}{|l|}{ Predictor importance, \% } \\
\hline Exposure & 100 & - & 60 & 48 \\
\hline Vulnerability & - & 100 & 40 & 21 \\
\hline Exposure $\times$ vulnerability & - & - & - & 31 \\
\hline$n$ & 16 & 24 & 16 & 16 \\
\hline$R^{2}$ (adjusted $R^{2}$ ), \% & $36(32)$ & $24(21)$ & $62(57)$ & $78(73)$ \\
\hline
\end{tabular}

(a)

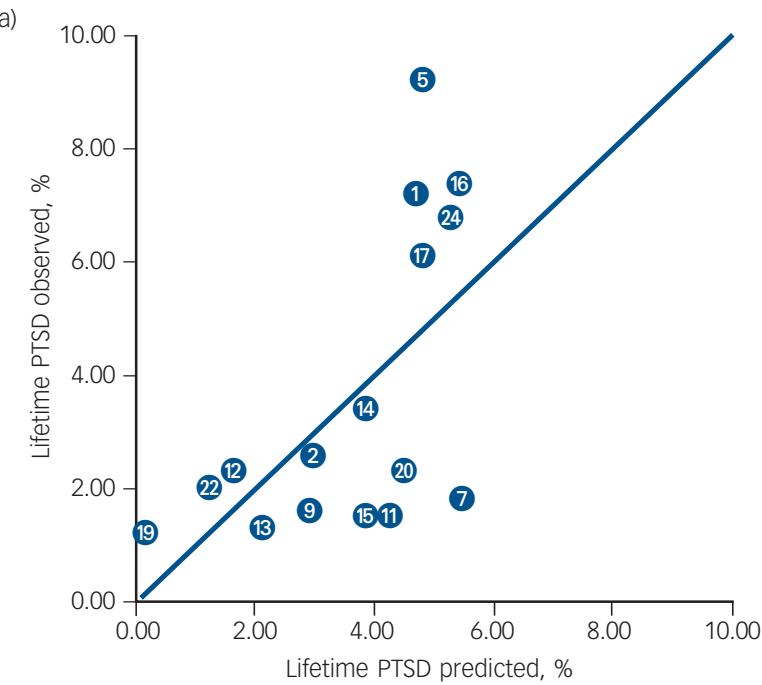

(C)

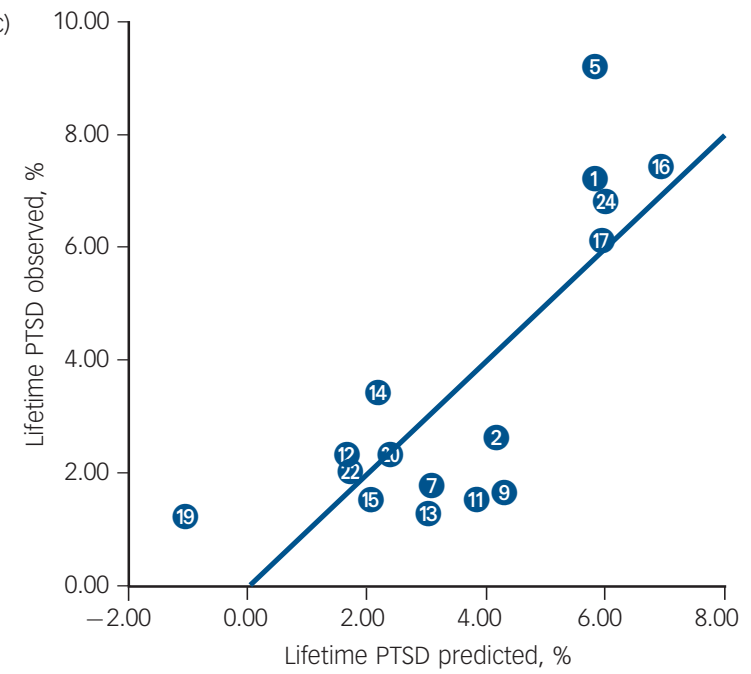

(b)

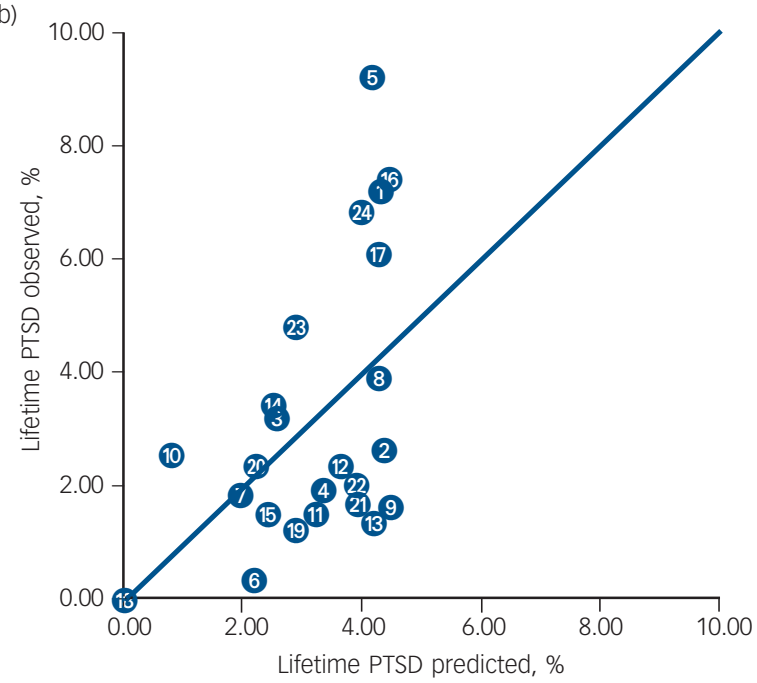

(d)

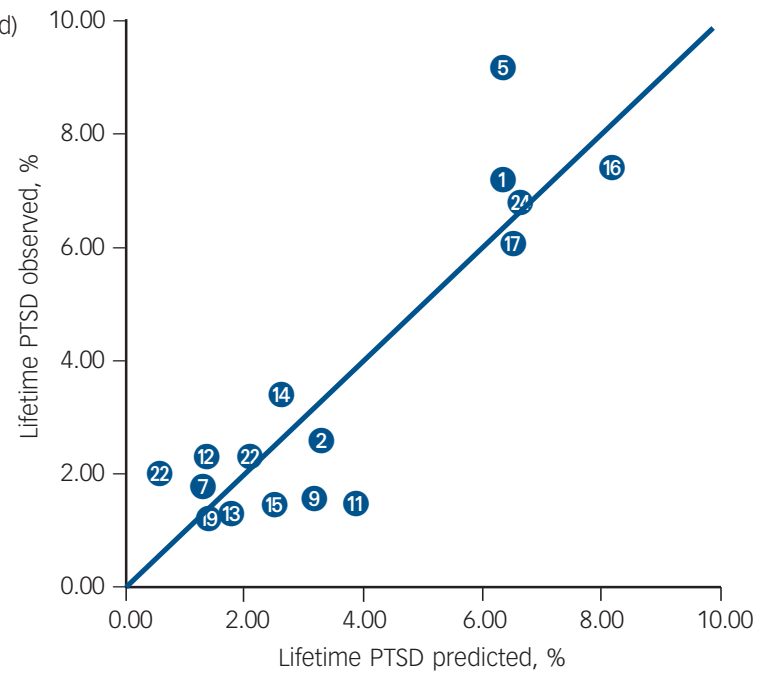

Fig. 2 Lifetime post-traumatic stress disorder (PTSD) predicted in four models.

The four models tested in this study are shown in four quadrants, each displaying the association between observed lifetime PTSD prevalence ( $y$-axis) and predicted lifetime PTSD prevalence ( $x$-axis). The predicted prevalence is based on (a) Model 1: exposure; (b) Model 2: vulnerability; (c) Model 3: exposure and vulnerability, and (d) Model 4: exposure moderated by vulnerability. 1, Australia; 2, Belgium; 3, Brazil; 4, Bulgaria; 5, Canada; 6, China; 7, Colombia; 8, France; 9, Germany; 10, Iraq; 11, Israel; 12, Italy; 13, Japan; 14, Lebanon; 15, Mexico; 16, The Netherlands; 17, New Zealand; 18, Nigeria; 19, Romania; 20, South Africa; 21, South Korea; 22, Spain; 23, Ukraine; 24, USA. 
when country vulnerability was low. About $75 \%$ of the variance in PTSD was explained in the final model.

Survey response rates were not correlated with PTSD or exposure rates, but strongly correlated with vulnerability $(r=0.71, P<0.01)$; more vulnerable countries had higher response rates. Inclusion of response rates in the regression models did not affect the results.

The average trauma exposure and vulnerability rates of the 16 countries are 67.14 and 36.23, respectively. Based on these averages countries can be divided into four groups (Fig. 3). As the pattern found in model 4 indicates (Fig. 2), Australia, Canada, The Netherlands, New Zealand and the USA have a fairly high average lifetime PTSD of 7.34\%. These five countries were characterised by higher rates of exposure and lower vulnerability levels.

The other 11 countries clustered together around a lower PTSD average, but their exposure and vulnerability profiles were not homogeneous. Belgium, Germany, Italy, Japan and Spain were characterised by lower exposure and vulnerability with a PTSD average of $1.96 \%$. A third group of five countries had an equivalent PTSD average of $2.1 \%$ and were characterised by higher exposure and vulnerability: Colombia, Israel, Lebanon, Mexico and South Africa. With its fairly low exposure and high vulnerability profile Romania did not belong with any of the other countries.

In the scatterplots based on models 1 and 2 (Fig. 2), we see that exposure and vulnerability as single predictors underestimated lifetime PTSD in 'high exposure-low vulnerability' populations. A prediction based on exposure alone overestimated lifetime PTSD in case of 'high exposure-high vulnerability'. The prediction based on vulnerability appeared to overestimate lifetime PTSD in 'low exposure-low vulnerability' populations. The model with both predictors yielded a more accurate estimate, although Romania's predicted negative lifetime PTSD rate was unrealistic. The interaction term corrected this in the final model.

\section{Discussion}

The current study replicated the individual-level positive relation between exposure to trauma and PTSD prevalence at the country level but identified a 'vulnerability paradox': whereas higher vulnerability is associated with increased PTSD at individual ${ }^{1}$ and group ${ }^{8}$ levels, it shows the opposite association at a country level. The average lifetime PTSD in 'low exposure-low vulnerability' and 'high exposure-high vulnerability' populations are similar. Average PTSD prevalence in 'high exposure-low vulnerability' countries is more than three times as high.
Before we further explore the relevance of these findings it is important to emphasise the need for caution in interpreting the pattern found and to encourage replication. Beyond doubt, comparing population studies from different countries is methodologically challenging as language issues, and demographic and cultural properties can affect the validity and comparability of measurements that reflect an isolated moment in time. For example, the vulnerability effect could be biased by language: four of the five 'high exposure-low vulnerability' countries are Englishspeaking. Steel et al identified high lifetime rates of mental illness in English-speaking countries. ${ }^{14}$ However, we found other population studies from non-English-speaking countries that, although they did not meet our inclusion criteria, reveal PTSD prevalence and exposure rates conforming to the pattern identified in our analyses. Three studies (not using the CIDI) fall within the 'high exposure-low vulnerability' group and reported similarly high rates of PTSD: Portugal (PTSD 7.9\%, exposure $75.7 \%$, vulnerability $34.8 \%$ ), ${ }^{15}$ Sweden (PTSD 5.6\%, exposure $80.8 \%$, vulnerability $28.4 \%)^{16}$ and Denmark (adolescents: PTSD $7.7 \%$, exposure $78 \%$, vulnerability $28.5 \%) .^{17}$

Apart from the language issue we checked whether alternative available data-sets corroborated the findings. An earlier general population survey found that the lifetime PTSD prevalence in The Netherlands was 4.0, ${ }^{18}$ with an exposure rate of $61.9 .{ }^{12}$ Both lifetime PTSD and exposure were lower than those reported by De Vries \& Olff, ${ }^{19}$ whose study was included in our analysis. However, when repeating the analysis using this earlier population sample, the effects remained unaltered and significant. We followed the same procedure with earlier survey data from the USA that pointed to a slightly different lifetime PTSD prevalence score of $7.8 \%$ in the general population (DSM-III). ${ }^{20}$ Using the older percentage did not result in a different outcome either.

Additionally, we explored the presence of the paradox in the context of mood disorders (for example depression). Based on the WMH survey data Kessler and colleagues reported the lifetime prevalence of mood disorders in 17 countries. $^{21}$ We combined these prevalence rates with the country vulnerability scores from the 2013 World Risk Report. The negative correlation between mood disorder prevalence and vulnerability points to a similar paradox ( $r=-0.58, P<0.05, n=17)$. The correlation is even higher than the correlation between PTSD and vulnerability (Table 1). As a next step we tested the group averages based on exposure and vulnerability scores. The average mood disorder prevalence in 'high exposure-low vulnerability' countries (The Netherlands, New Zealand and USA, 19.9\%) is higher than in the 'high exposure-high vulnerability' (Colombia, Israel, Lebanon, Mexico

\begin{tabular}{|c|c|c|}
\hline & $\begin{array}{l}\text { High vulnerability } \\
\qquad(>36.23)\end{array}$ & $\begin{array}{l}\text { Low vulnerability } \\
\qquad(<36.23)\end{array}$ \\
\hline $\begin{array}{l}\text { High exposure } \\
(>67.14)\end{array}$ & $\begin{array}{l}\text { Colombia, Israel, Lebanon, } \\
\text { Mexico, South Africa } \\
\text { Average lifetime PTSD: } 2.1 \%\end{array}$ & $\begin{array}{c}\text { Australia, Canada, The Netherlands, } \\
\text { New Zealand, USA } \\
\text { Average lifetime PTSD: } 7.34 \%\end{array}$ \\
\hline $\begin{array}{l}\text { Low exposure } \\
(<67.14)\end{array}$ & $\begin{array}{c}\text { Romania } \\
\text { Average lifetime PTSD: } 1.2 \%\end{array}$ & $\begin{array}{l}\text { Belgium, Germany, Italy, } \\
\text { Japan, Spain } \\
\text { Average lifetime PTSD: } 1.96 \%\end{array}$ \\
\hline
\end{tabular}


and South Africa, 11.38\%) and 'low exposure-low vulnerability' (Belgium, Germany, Italy, Japan and Spain, 10.42\%) groups (ANOVA with Bonferroni post hoc test: $P<0.01, n=13$ ).

All in all, our findings cannot readily be accounted for by explanations applied to observed differences in the cross-national prevalence of mental disorders, such as limitations in Westernbased diagnostic assumptions or differences in the age structure of populations (N.B. life expectancy in more vulnerable countries is lower). ${ }^{14}$ The possible role of cultural and psychological factors should be taken seriously. Burri \& Maercker, for instance, succeeded in explaining substantial levels of variance in crossnational PTSD in 12 European countries (not using the CIDI) after including cultural value orientations. ${ }^{22}$ Moreover, based on an analysis of data from 60 countries, it has recently been suggested that over two-thirds of the variance in national vulnerability can be explained by cultural factors: less vulnerable countries are inhabited by more individualistic cultures with a more equal power balance, less uncertainty avoidance, a more long-term orientation, higher indulgence and less restraint. ${ }^{23}$ Although these factors may have an impact on responses to diagnostic instruments such as the CIDI, it is conceivable that such cultures may be lacking aspects of social capital such as community engagement and support that could help victims of trauma repair their resources and rebuild their lives. ${ }^{24}$ This contrasts with the expectation that less vulnerable countries should be better equipped to anticipate a higher burden of disease, and should be more favourably placed to overcome barriers on the path to equitable care. ${ }^{25}$

Another explanation for a higher conditional PTSD prevalence in low vulnerability countries might be that the relative impact of a traumatic event on long-term goals is greater, because there is more expectation of achieving such goals. This account is consistent with classic research linking greater status striving and aspiration-achievement discrepancies to mental illness. ${ }^{26}$ Our findings may also be related to theories that PTSD represents an overturning of basic assumptions about self-worth, and about the meaningfulness, predictability and benevolence of the world. ${ }^{27}$ Countries high in vulnerability may foster conditions that minimise comforting illusions and reduce the contradictions brought about when cherished assumptions are invalidated by traumatic events.

We believe that more detailed investigation of the vulnerability paradox and its possible theoretical interpretations may not only throw light on the nature of PTSD but also proffer important clues about the nature of resilience to trauma that could be harnessed for general benefit. Specifically, it raises the possibility that vulnerability as measured through deprivation may be an index of greater resilience rather than lesser resilience as is commonly assumed.

\section{Strengths and weaknesses}

It is one of the strengths of this study that researchers everywhere in the world can access the national surveys as well as the vulnerability data. We applied a stepwise approach to make the changes in predicted PTSD in each successive step transparent. Since the main predictors - exposure and vulnerability - are unrelated, confounding is unlikely. We also demonstrated that the results were not specific to a single set of surveys or to the PTSD diagnosis alone, and ruled out various other potential confounding factors such as English $v$. non-English speaking status and differential response rates. The analysis was nevertheless based on only 24 countries with information on lifetime PTSD and a subsample of 16 countries with available exposure data. This enjoins caution in drawing inferences from the data, especially because the average vulnerability of the 16 countries (36.23) is lower than the worldwide average of the 173 countries in the 2013 World Risk Report (48.56, range 27.30-75.41). The limited sample makes an extensive assessment of particular vulnerability characteristics or other country features problematic.

Another issue to keep in mind in interpreting the findings is that one CIDI-based measure of overall trauma exposure was used. This can be seen as a strength, yet in reality countries vary in their types of exposure, and exposure types vary substantially in the likelihood that they will lead to PTSD. Therefore, two countries that have the same level of exposure but different types of exposure underlying the total percentage exposed measure might have a different risk of PTSD. With only five publications included in our study containing information on different types of exposure to trauma rigorous comparisons were not possible.

When it comes to the PTSD and exposure data, several advantages of the CIDI have been addressed. At the same time, the absence of PTSD in Nigeria is puzzling and it is worthwhile considering the explanations for a possible underrepresentation provided by Gureje et al. ${ }^{28}$ One of their explanations is that in a setting where mental illness is still highly stigmatised, symptoms of such illness might be embarrassing and so more likely to be denied. A second explanation could be that respondents might not feel comfortable disclosing their symptoms to a lay interviewer and thus keep important information to themselves. ${ }^{28}$ Stigma and reservations might, and this could apply to any and all the countries, form a stronger explanation in more vulnerable countries that are, again, more collectivistic and with a less equal power balance. ${ }^{23}$ It would be interesting to combine country vulnerability with population data on stigma in relation to mental health problems and to explore this association (for example, the Stigma in Global Context - Mental Health Study; see Pescosolido et $a l^{29}$ ).

Although the data-set is based on thousands of respondents, we were limited to using aggregated individual scores at country level, and could not work with the original data-sets. Unfortunately, we were unable to examine individual-, group- and country-level characteristics simultaneously with more advanced analysis techniques incorporating a multilevel approach, while taking factors such as gender, age, socioeconomic or marital status into account. It could be informative to bring the original data-sets together and further assess the variance in PTSD at different levels in relation to other health issues, types of exposure and risk and protective factors.

Finally, some limitations of the world vulnerability index must be mentioned. An array of data-sets from different sources are used to bring together social and economic dimensions and natural hazard analysis in the vulnerability index. The data-sets used are not designed for this purpose; they are incorporated simply because they are available. ${ }^{30}$ That said, indicators have been assigned to three constructs with a good reliability coefficient and the index has been thoroughly tested. ${ }^{31}$ Although the index is a helpful source to understand disaster risk internationally, the statistical work on it is still in progress and there is scope for a follow-up analysis covering more relevant data. The correlation between the vulnerability scores in the $2012^{32}$ and the 2013 report is almost perfect $(r=0.998, n=173)$, suggesting that the vulnerability index is stable. This might be important given the gap between the years of data collection for the trauma prevalence rates and the later created vulnerability construct. Changes over time in country vulnerability might affect its relationship to the prevalence of lifetime PTSD.

In conclusion, we tested multiple models to explain the prevalence of lifetime PTSD in different countries. The analysis suggests that the effect of exposure on PTSD is moderated by 
the level of vulnerability. Paradoxically, in the context of high trauma exposure, the populations of less vulnerable countries with more resources and better healthcare have higher chances of developing PTSD in their lifetime.

Michel L. A. Dückers, PhD, Impact - National Knowledge and Advice Centre for Psychosocial Care Concerning Critical Incidents, Arq Psychotrauma Expert Group, Diemen, and NIVEL- Netherlands Institute for Health Services Research, Utrecht, The Netherlands; Eva Alisic, PhD, Monash University Accident Research Centre, Monash University, Melbourne, Australia; Chris R. Brewin, PhD, Department of Clinical, Educational and Health Psychology, University College London, London, UK

Correspondence: Michel Dückers, NIVEL - Netherlands Institute for Health Services Research, Otterstraat 118-124, 3513 CR, Utrecht, The Netherlands. Email: m.duckers@nivel.n!

First received 6 Oct 2015, final revision 31 Mar 2016, accepted 7 Apr 2016

\section{References}

1 Brewin CR, Andrews B, Valentine JD. Meta-analysis of risk factors for post-traumatic stress disorder in trauma-exposed adults. J Consult Clin Psychol 2000; 68: 748-66.

2 Brewin CR, Holmes EA. Psychological theories of posttraumatic stress disorder. Clin Psychol Rev 2003; 23: 339-376.

3 Ozer EJ, Best SR, Lipsey TL, Weiss DS. Predictors of post-traumatic stress disorder and symptoms in adults: a meta-analysis. Psychol Bull 2003; 129: 52-73.

4 Yehuda R. Post-traumatic stress disorder. N Engl J Med 2002; 346: 108-14.

5 Kessler RC, Ustun TB. The WHO World Mental Health Surveys: Global Perspectives on the Epidemiology of Mental Disorders. Cambridge University Press, 2008.

6 Cutter SL. Living with Risk. Edward Arnold, 2008.

7 Welle T, Birkmann B, Rhyner J, Witting M, Wolfertz J. World Risk Index 2013. In World Risk Report 2013: 45-56. Alliance Development Works, 2013 (http://www.worldriskreport.org/fileadmin/PDF/2013/WorldRiskReport_2013_ online.pdf).

8 Bonanno GA, Brewin CR, Kaniasty K, La Greca AM. Weighing the costs of disaster: consequences, risks, and resilience in individuals, families, and communities. Psychol Sci Public Interest 2010; 11: 1-49.

9 Hobfoll SE, Palmieri PA, Robert J, Canetti-Nisim D, Hall BJ, Galea S. Trajectories of resilience, resistance, and distress during ongoing terrorism: the case of Jews and Arabs in Israel. J Consult Clin Psychol 2009; 77: 138-48.

10 World Health Organization. Composite International Diagnostic Interview (CIDI) (Version 2.1). WHO, 1997

11 Kessler RC, Ustun B. The World Mental Health (WMH) survey initiative version of the World Health Organization (WHO) Composite International Diagnostic Interview (CIDI). Int J Method Psychiatr Res 2004; 13: 93-121.

12 Scott KM, Koenen KC, Aguilar-Gaxiola S, Alonso J, Angermeyer MC, Benjet C, et al. Associations between lifetime traumatic events and subsequent chronic physical conditions: a cross-national, cross-sectional study. PLOS One 2013; 11: e80573.

13 Kessler RC, Rose S, Koenen KC, Karam EG, Stang PE, Stein DJ, et al. How well can post-traumatic stress disorder be predicted from pre-trauma risk factors? An exploratory study in the WHO World Mental Health Surveys. World Psychiatry 2014; 13: 265-74.
14 Steel Z, Marnane C, Iranpour C, Chey T, Jackson JW, Patel V, et al. The global prevalence of common mental disorders: a systematic review and metaanalysis 1980-2013. Int J Epidemiol 2014; 43: 476-93.

15 De Albuquercue A, Soares C, Martins De Jesus P, Alves C. The epidemiology of PTSD in the adult population in Portugal. Acta Médica Portuguesa 2003; 16: $309-320$.

16 Frans Õ, Rimmö P-A, Åberg L, Fredrikson M. Trauma exposure and posttraumatic stress disorder in the general population. Acta Psychiatr Scand 2005; 111: 291-9.

17 Elklit A, Frandsen LB. Trauma exposure and posttraumatic stress among Danish adolescents. J Trauma Stress Disor Treat 2014; 3: 4.

18 De Graaf R, Ormel J, Ten Have M, Burger H, Buist-Bouwman M. Mental disorders and service use in the Netherlands: results from the European Study of the Epidemiology of Mental Disorders (ESEMeD). In The WHO World Mental Health Surveys: Global Perspectives on The Epidemiology of Mental Disorders (eds RC Kessler, TB Ustun): 388-405. Cambridge University Press, 2008.

19 De Vries GJ, Olff M. The lifetime prevalence of traumatic events and posttraumatic stress disorder in the Netherlands. J Trauma Stress 2009; 22: $259-67$

20 Kessler RC, Sonnega A, Bromet E, Hughes M, Nelson CB. Posttraumatic stress disorder in the National Comorbidity Survey. Arch Gen Psychiatry 1995; 52: 1048-60.

21 Kessler RC, Aguilar-Gaxiola S, Alonso J, Chatterji S, Lee S, Ormel J, et al The global burden of mental disorders: an update from the WHO World Mental Health (WMH) surveys. Epidemiol Psichiatr Soc 2009; 18: 23-33.

22 Burri A, Maercker A. Differences in prevalence rates of PTSD in various European countries explained by war exposure, other trauma and cultura value orientation. BMC Res Notes 2014; 7: 407.

23 Dückers M, Frerks G, Birkmann J. Exploring the plexus of context and consequences: an empirical test of a theory of disaster vulnerability. Int J Disaster Risk Red 2015; 13: 85-95.

24 Durant TJ. The utility of vulnerability and social capital theories in studying the impact of hurricane Katrina on the elderly. J Fam Issues 2011; 32 1285-302.

25 Dückers MLA, Witteveen AB, Bisson Jl, Olff M. The association between disaster vulnerability and post-disaster psychosocial service delivery across Europe. Adm Policy Ment Health 2015; July 22 (Epub ahead of print).

26 Kleiner RJ, Parker S. Goal-striving, social status, and mental disorder: a research review. Am Sociol Rev 1963; 28: 169-203.

27 Janoff-Bulman R. Shattered Assumptions: Towards a New Psychology of Trauma. The Free Press, 1992.

28 Gureje O, Lasebikan VO, Kola L, Makanjuola VA. Lifetime and 12-month prevalence of mental disorders in the Nigerian Survey of Mental Health and Well-Being. Br J Psychiatry 2006; 188: 465-71.

29 Pescosolido BA, Medina TR, Martin JK, Long JS. The "backbone" of stigma: identifying the global core of public prejudice associated with mental illness. Am J Public Health 2013; 103: 853-60.

30 Heesen J, Lorenz DF, Nagenborg M, Wenzel B, Voss M. Blind spots on Achilles' heel: the limitations of vulnerability and resilience mapping in research. Int J Disaster Risk Science 2014; 5: 74-85.

31 Alliance Development Works. Methods Used. Alliance Development Works 2012 (http://www.worldriskreport.org/fileadmin/WRB/PDFs_und_Tabellen/ Methods_used_15.pdf).

32 Welle T, Birkmann J, Rhyner J, Witting M, Wolfertz J. World Risk Index 2012: concept, updating and results. In World Risk Report 2012: 11-26. Alliance Development Works, 2012. (http://www.worldriskreport.org/fileadmin/WRB/ PDFs_und_Tabellen/WRR_2012 en_online_01.pdf). 